\title{
PRODUCTION OF CROSS-REACTIVE AUTOANTIBODY BINDING TO BOVINE SERUM ALBUMIN IN THE D- GALACTOSE-INDUCED AGING MOUSE MODEL
}

\author{
${ }^{1}$ Ji-Hun Park and ${ }^{1,2}$ Tae-Saeng Choi \\ ${ }^{1}$ Department of Nanobiomedical Science and WCU Research Center of Nanobiomedical Science, Korea \\ ${ }^{2}$ Department of Microbiology, College of Medicine, Dankook University, Anseo, Cheonan 330-714, Korea
}

Received 2013-12-23; Revised 2014-01-07; Accepted 2014-01-13

ABSTRACT

The D-galactose (D-gal)-induced animal model, generated by repeated subcutaneous D-gal injections over approximately 6 weeks, has been frequently used for diabetes and aging research. However, little research has investigated the direct correlation between D-gal and autoantibody formation despite several reports on diabetes-and aging-related autoantibodies. The purpose of this study was to determine whether repetitive injection of D-gal can induce autoantibody production in mice. First, we used Bovine Serum Albumin (BSA) and Advanced Glycation End products (AGE)-BSA as the test antigens. The immunoreactivity of serum samples from mice treated with D-gal for 6 weeks was evaluated using Enzyme-Linked Immunosorbent Assay (ELISA). We found that serum samples of D-gal-treated mice had significantly high antibody titers against both BSA and AGE-BSA. Furthermore, the result showed that aminoguanidine treatment, an AGE inhibitor tended to decrease this immunoreactivity. The results of competitive inhibition ELISA using BSA and AGE-BSA as the competitors suggested that the serum samples from D-gal-treated mice contained antibodies not only against BSA but also specific to AGEBSA. To assess whether the immunoreactivity against BSA is comparable to that against Mouse Serum Albumin (MSA), we examined the reactivity of D-gal-induced antibodies against MSA. Unexpectedly, D-gal-induced antibodies did not react with MSA. This suggests that the production of antibodies by Dgal is in response to an unknown antigen(s), aside from MSA, in mice and that this unknown antigen(s) may share similar sequences or three-dimensional structures with BSA.

Keywords: D-Galactose-Induced Aging Model, Advanced Glycation End Products, Autoantibody, Bovine Serum Albumin, Mouse Serum Albumin

\section{INTRODUCTION}

Advanced Glycation End products (AGEs) are formed in vivo by the Maillard reaction, a non-enzymatic reaction of proteins or lipids with carbohydrates (Horiuchi et al., 1991). Many studies on AGEs have been conducted in diabetes models (Berg et al., 1997; Rumble et al., 1997; Cooper, 2004), with chronic high blood sugar levels and in aging models (Shuvaev et al., 2001; Odetti et al., 2005; Luevano-Contreras and Chapman-Novakofski, 2010), each displaying gradual accumulation of AGEs. For example, AGEs such as N- (carboxymethyl) Lysine (CML) and pentosidine have been found to accumulate on proteins of the skin and lens at accelerated rates in diabetic and aged tissues (Dyer et al., 1993; Handa et al., 1999). In this regard, the D-gal-induced aging model was established by artificially inducing high levels of AGEs through repetitive injections of highly concentrated carbohydrates (Song et al., 1999).

The D-gal-induced aging mouse model was produced by consecutive subcutaneous D-gal injections over approximately 6 weeks (Song et al., 1999). This animal model shows accelerated aging in the brain, ear, kidney,

Corresponding Author: Tae-Saeng Choi, Department of Microbiology, College of Medicine, Dankook University, Anseo,

Cheonan 330-714, Korea Tel: +82-41-550-3872 Fax: +82-41-550-3864 
liver and blood cells (Lei et al., 2008; Xie and Ling, 2008; Aydin et al., 2012; Hsia et al., 2012; Wu et al., 2012) more recently, we found phenotypes of Polycystic Ovary Syndrome (PCOS) in this model (Park and Choi, 2012). These induced phenotypes may be the result of excessive formation of Reactive Oxygen Species (ROS) and D-gal-induced accumulation of AGEs (Song et al., 1999). ROS damage and AGE accumulation are well known causes of aging and diabetes (Osawa and Kato, 2005; Nass et al., 2007). In addition, many autoantibodies associated with diabetes and aging have been detected (Morohoshi et al., 2012; Ziegler and Bonifacio, 2012; Culina et al., 2013). However, autoantibody production in this model has not yet been reported.

Antibody production in vivo occurs in response to the invasion of foreign material, such as harmful bacteria or viruses, as well as to the appearance of modified selfproteins. AGEs could be an example of the latter case, although the direct correlation among excessive carbohydrates, AGEs and their autoantibodies has not been verified to date. Previous studies have demonstrated antibody production in response to CML-BSA in diabetic human patients (Shibayama et al., 1999) as well as higher antigenicity of AGE-IgG than IgG (Rasheed et al., 2009).

In this study, we hypothesized that certain AGE(s), created by repetitive injection of excess D-gal into mice, can stimulate autoantibody production. To prove this hypothesis, we tested for autoantibodies against BSA or AGE-BSA, the latter of which we have already isolated. The results showed significantly high antibody titers against BSA and AGE-BSA in blood samples of D-gal-treated mice. Additional tests showed the antibodies did not react against Mouse Serum Albumin (MSA). Taken together, these results suggest that the production of antibodies by repetitive injection of D-gal is due to unknown mouse protein(s), aside from MSA and the neo-epitopes of the unknown mouse protein(s) may share identical sequence(s) or three-dimensional structure(s) with BSA.

\section{MATERIALS AND METHODS}

\subsection{Animals and D-Gal Treatment}

ICR female mice aged 8-10 weeks were used for this study. The mice were provided drinking water ad libitum and a normal diet and kept under a 12-h light-dark cycle at $24 \pm 1{ }^{\circ} \mathrm{C}$ and $50 \%$ humidity. Mice were randomly divided into three groups containing five mice each. After a 1-week adaptation period, mice from each group were injected subcutaneously daily with $1,000 \mathrm{mg} \mathrm{kg}^{-1}$ D-gal or vehicle $(0.9 \%$ saline $)$ as a control for approximately 6 weeks (Park and Choi, 2012). One of the D-gal-treated groups was continually administered $0.1 \%$ aminoguanidine, an AGE inhibitor, in the drinking water. All animal studies were conducted in compliance with the guidelines for the Care and Use of Research Animals established by the Animal Studies Committee of Dankook University.

For blood plasma preparation, whole blood was obtained by incising the tail vein with a sharp surgical blade and then centrifuged at $1,500 \times \mathrm{g}$ for $15 \mathrm{~min}$ at room temperature. The plasma was aliquoted and frozen at $-80^{\circ} \mathrm{C}$ until use.

\subsection{AGE-BSA Production}

AGE-BSA was prepared as described previously (Wang et al., 2011). In brief, $50 \mathrm{mg} \mathrm{mL}^{-1}$ fatty acid-free BSA (Sigma-Aldrich) was incubated with $0.5 \mathrm{M}$ glucose in $10 \mathrm{mM}$ PBS containing $0.5 \mathrm{mM}$ EDTA, 100 units $\mathrm{mL}^{-1}$ penicillin, $100 \mu \mathrm{g} \mathrm{mL}^{-1}$ streptomycin, $\mathrm{pH} 7.4$ at $37^{\circ} \mathrm{C}$ for 12 weeks under sterile conditions. Nonglycated BSA was prepared under the same conditions but without glucose. After incubation for 12 weeks, unincorporated sugar was removed by dialysis against PBS for $24 \mathrm{~h}$. The prepared AGE-BSA and BSA were sterilized by ultrafiltration and stored at $-70^{\circ} \mathrm{C}$ until use.

\subsection{Enzyme-Linked Immunosorbent Assay (ELISA)}

ELISA was performed in 96-well polystyrene plates. The plate was coated with $100 \mu \mathrm{L}$ of the $20 \mu \mathrm{g} \mathrm{mL}^{-1} \mathrm{BSA}$, AGE-BSA, or MSA (Sigma Aldrich) in $0.05 \mathrm{~mol} \mathrm{~L}^{-1}$ carbonate-bicarbonate buffer, $\mathrm{pH}$ 9.6. The plates were incubated for $2 \mathrm{~h}$ at $37^{\circ} \mathrm{C}$ or overnight at $4^{\circ} \mathrm{C}$. Unbound antigen was washed three times with PBS-T (20 mM PBS, $\mathrm{pH} 7.4,0.05 \%$ Tween-20) and the unoccupied sites were blocked with $2 \%$ nonfat milk in PBS-T for $1 \mathrm{~h}$ at room temperature. After incubation, the plates were washed again three times with PBS-T. To quantitate the antibodies in serum, serial two-fold dilutions were used ranging from $1: 400$ to $1: 3200$. Diluted test serum was added to the antigen-coated wells and re-incubated for $2 \mathrm{~h}$ at room temperature or overnight at $4^{\circ} \mathrm{C}$. Bound $\mathrm{IgG}$ antibodies were measured using the ELISA colorimetric detection kit (KPL, BluePhos ${ }^{\circledR}$ Microwell Phosphatase Substrate System). The absorbance of each well was measured at $595 \mathrm{~nm}$ with an automatic microplate reader and the mean of duplicate readings for each sample was recorded.

For competition ELISA, the plate was coated with 20 $\mu \mathrm{g} \mathrm{mL}^{-1}$ AGE-BSA. Varying concentrations (0, 10, 100, $1000 \mu \mathrm{g} \mathrm{mL}^{-1}$ ) of BSA or AGE-BSA were pre-incubated 
with 400-fold diluted mouse serum for $2 \mathrm{~h}$ at room temperature and the mixture was subsequently added to the antigen-coated plates. The remaining steps were the same as that for standard ELISA. Percentage inhibition was calculated as 1- (A inhibited/A uninhibited $) \times 100$.

\subsection{Statistical Analyses}

Statistical differences among groups were analyzed using a one-way Analysis of Variance (ANOVA). Data are shown as the means \pm Standard Error of the Mean (SEM) and significance was defined as $\mathrm{p}<0.05$.

\section{RESULTS}

\subsection{Antibody Production Against BSA and AGE-BSA in D-Gal Treated Mice}

The immunoreactivity against BSA and AGE-BSA was tested using ELISA. Blood samples were serially diluted from 1:400 to 1:3200. The antibody titers against BSA and AGE-BSA were significantly high and similar for both antigens (Fig. 1). In contrast, decreased antibody titers were detected in serum samples from mice treated simultaneously with D-gal and aminoguanidine. These results showed that antibodies were produced against BSA and AGE-BSA in the serum of D-gal-treated mice and that the production of antibodies may be due to the formation of AGEs.

\subsection{Inhibition of Antibody Binding to AGE- BSA by Pretreatment of Serum with BSA or AGE-BSA}

To investigate whether an antibody specific to AGEBSA exists among those induced by treatment of mice with D-gal, we performed competitive inhibition ELISA. We used AGE-BSA as the antigen and pre-incubated the serum samples with varying concentrations of BSA or AGE-BSA as the first antibody. Inhibition rates were markedly higher with pre-incubation of AGE-BSA (27 and $47 \%$ ) compared with that of BSA (5 and 27\%) at 10 and $100 \mu \mathrm{g} \mathrm{mL} \mathrm{mL}^{-1}$, respectively (Fig. 2). The results indicate the existence of a specific antibody for AGE-BSA among those induced by D-gal treatment.

\subsection{D-Gal-Induced Antibodies do not Cross- React with MSA}

To evaluate whether the antibodies induced by D-gal treatment interact with not only BSA but also MSA, we performed ELISA using MSA as the ELISA antigen. As shown in Fig. 3, the antibodies showed no reactivity against MSA.

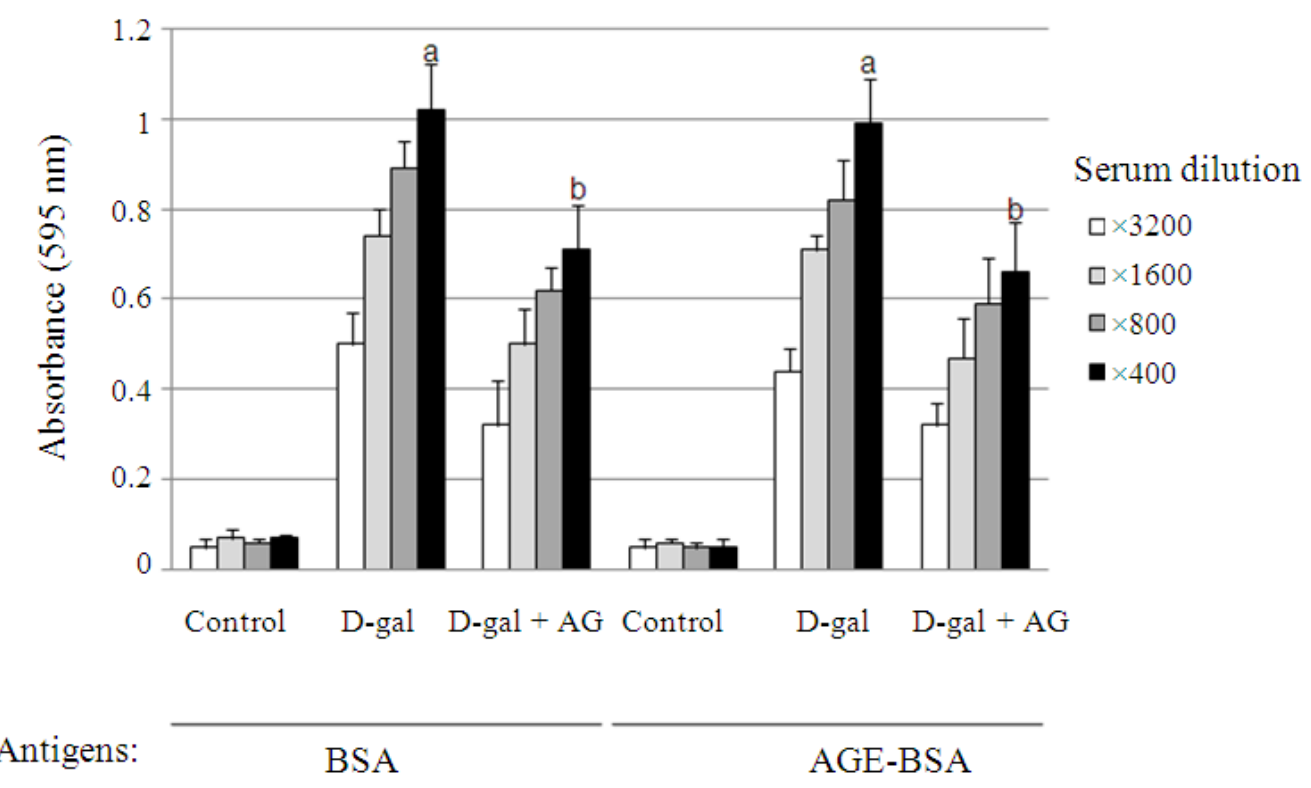

Fig. 1. Immunoreactivity to AGE-BSA and BSA of serum of D-gal-treated mice. Serum samples from each mouse group were diluted as indicated and tested for immunoreactivity against AGE-BSA and BSA using ELISA. Data represent the mean \pm S.E.M. of five mice per group. The different superscripts represent significantly different values $(\mathrm{p}<0.05)$. Aminoguanidine (AG), D-galactose (D-gal) 


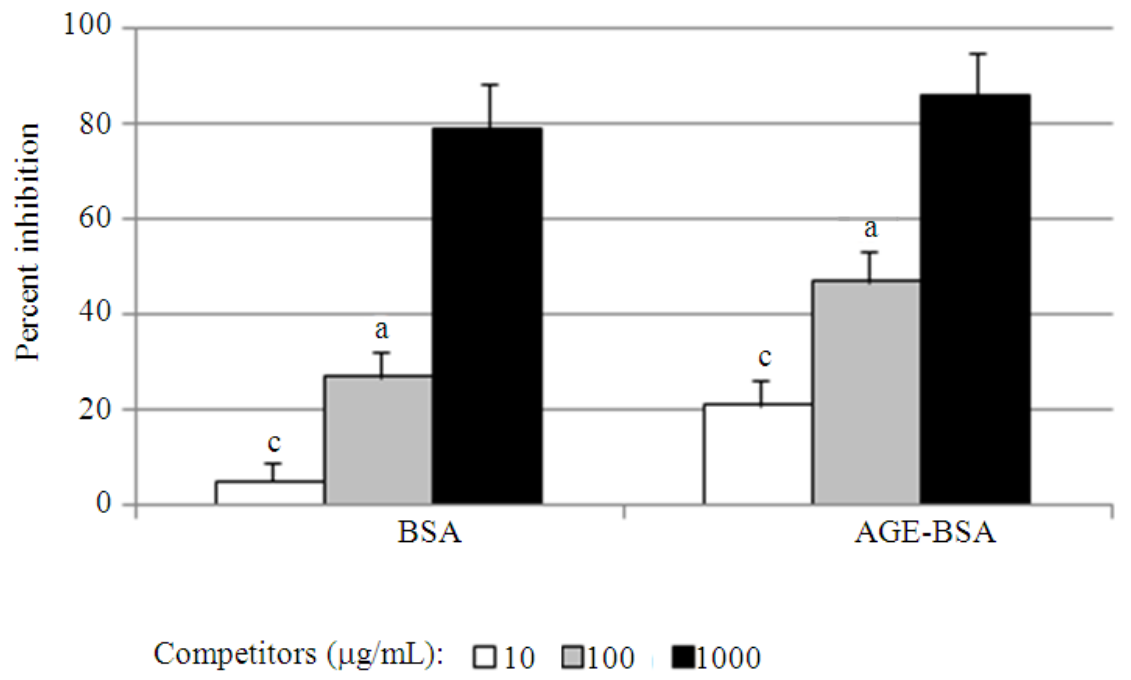

Fig. 2. Inhibition of D-gal-induced antibody binding to the AGE-BSA antigen using free BSA or AGE-BSA as the competitor. The microtiter plates were coated with AGE-BSA $\left(20 \mu \mathrm{gL}^{-1}\right)$. Inhibition of D-gal-induced antibody binding to AGEBSA was measured by pre-incubation of the serum with competitors (free BSA or AGE-BSA) at the indicated concentration. The percent inhibition was calculated as described in the Materials and Methods. Data represent the means \pm S.E.M. of five mice per group. Different superscripts represent significantly different values $(\mathrm{p}<0.05)$

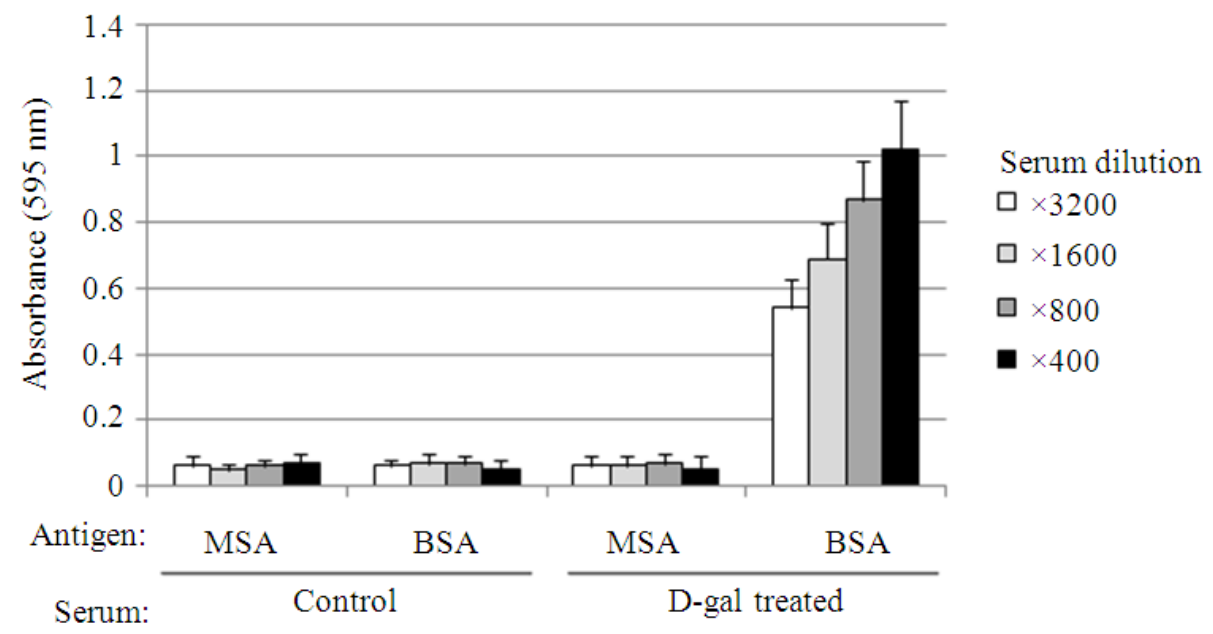

Fig. 3. Immunoreactivity of the serum of D-gal-treated mice to Mouse Serum Albumin (MSA) and BSA. Serum samples from each mouse group were diluted as indicated and tested for immunoreactivity against BSA using ELISA. Data represent the means \pm S.E.M. of five mice per group

\section{DISCUSSION}

Autoantibody formation is a critical cause of autoimmune diseases and many autoantibodies have been associated with diabetes and aging (Wasserfall and Atkinson, 2006; Kay, 2013). It occurs when an antibody against invasive harmful bacteria or viruses interacts with self-proteins that have similar epitopes or those that are modified. As an example of the latter, recent study have suggested the possibility that AGEs produced by non-enzymatic reactions in vivo serve as antigens for autoantibody formation (Turk et al., 2001). In this respect, our results showed another example of autoantibody production caused by excessive AGE 
formation in vivo, although the protein antigen(s) was not identified by this study.

Our first hypothesis was that the production of autoantibodies against MSA, which is readily glycated and a precursor for AGE formation, occurs in D-gal-treated mice. We examined the formation of autoantibodies against BSA or AGE-BSA first because we have previously isolated AGE-BSA. We found high antibody titers against BSA and AGE-BSA in serum samples of Dgal-treated mice and this antibody production was presumed to relate to AGE formation, according to the results obtained from the aminoguanidine experiment (Fig. 2). The partial inhibitory effect on antibody production by aminoguanidine may be due to the higher concentrations of D-gal used in this study compared with previous reports (Song et al., 1999).

In addition, the results of the competitive inhibition ELISA using serum samples pre-incubated with free BSA or AGE-BSA showed that the antibodies were produced not only in response to BSA but also AGE-BSA. It appears that these antibodies were hapten- and carrierprotein-specific when immunization was performed with hapten-conjugated proteins. Recent studies have shown that AGEs possess immune potential and behave as do haptens (Bozhinov et al., 2012).

Refuting our first hypothesis, the antibodies did not at all cross-react with MSA (Fig. 3). The results suggest the possibility that an unknown protein susceptible to AGE(s), aside from MSA, serves as an epitope(s) for antibody production in D-gal-treated mice and that this epitope(s) corresponds to an epitope(s) of BSA.

Previous studies demonstrated that production of BSA antibodies in vivo is due to the consumption of cow's milk, which contains BSA (Ferguson, 1977; Helms and Rieger, 1987; Lerner et al., 1989). In addition, several reports suggested that the potential for BSA antibody formation is related to the onset of type I diabetes, during which BSA antibodies share a common epitope with the pancreatic islet cell surface protein ICA69 (Yokota et al., 1990; Pietropaolo et al., 1993). However, other studies showed contradictory results in regard to the relationships between BSA antibody and milk consumption or type I diabetes onset (Ronningen et al., 1998; Birgisdottir et al., 2002) currently, most researchers agree that there is no direct correlation between them (Scott et al., 1996). Nonetheless, the mechanism of BSA antibody production in vivo remains unknown. In this respect, our discovery of a D-gal-induced BSA antibody that does not exist and cannot be introduced in mice may provide new insight into this mechanism.

\section{CONCLUSION}

The present study found for the first time that BSA antibody production in the D-gal-induced aging mouse model. Furthermore, from the results of D-gal- induced antibodies did not react with MSA, this suggests that the production of antibodies by D-gal is in response to an unknown antigen(s), aside from MSA, in mice and that this unknown antigen(s) may share similar sequences or three-dimensional structures with BSA. Further studies against synthetic peptides derived from the sequence of BSA, which are not in MSA are needed to identify an unknown antigen(s).

\section{ACKNOWLEDGEMENT}

This study was funded by The Institute of Medical Science of Dankook University Medical Center in 2011.

\section{REFERENCES}

Aydin, S., K. Yanar, P. Atukeren, E. Dalo and M.E. Sitar et al., 2012. Comparison of oxidative stress biomarkers in renal tissues of D-galactose induced, naturally aged and young rats. Biogerontology, 13: 251-260. PMID: 22179795

Berg, T.J., H.J. Bangstad, P.A. Torjesen, R. Osterby and R. Bucala et al., 1997. Advanced glycation end products in serum predict changes in the kidney morphology of patients with insulin-dependent diabetes mellitus. Metabolism, 46: 661-665. PMID: 9186302

Birgisdottir, B.S., J.P. Hill, D.P. Harris and I. Thorsdottir, 2002. Variation in consumption of cow milk proteins and lower incidence of type 1 diabetes in Iceland Vs the other Nordic countries. Diabetes Nutr. Metab., 15: 240-245. PMID: 12416661

Bozhinov, A., Y. Handzhiyski, K. Genov, V. Daskalovska and T. Niwa et al., 2012. Advanced glycation end products contribute to the immunogenicity of IFN- $\beta$ pharmaceuticals. J. Allergy Clin. Immunol., 129: 855-858. PMID: 22154379

Cooper, M.E., 2004. Importance of advanced glycation end products in diabetes-associated cardiovascular and renal disease. Am. J. Htypertens., 17: 31s-38s. PMID: 15607433

Culina, S., V. Brezar and R. Mallone, 2013. Insulin and type 1 diabetes: Immune connections. Eur. J. Endocrinol., 168: 19-31. PMID: 23065992 
Dyer, D.G., J.A. Dunn, S.R. Thorpe, K.E. Bailie and T.J Lyons et al., 1993. Accumulation of maillard reaction products in skin collagen in diabetes and aging. J. Clin. Invest., 91: 2463-2469. PMID: 8514858

Ferguson, A., 1977. Immunogenicity of cows, milk in man. (Influence of age and of disease on serum antibodies to five cows' milk proteins). RIC Clin. Lab., 7: 211-219. PMID: 75562

Handa, J.T., N. Verzijl, H. Matsunaga, A. Aotaki-Keen and G.A. Lutty et al., 1999. Increase in the advanced glycation end product pentosidine in Bruch's membrane with age, Invest. Ophthalmol. Vis. Sci., 40: 775-779. PMID: 10067983

Helms, I. and C.H. Rieger, 1987. Decreased production of specific antibodies to cow's milk proteins in premature infants during the first six months of life. Eur. J. Pediatr., 146: 131-134. PMID: 3569348

Horiuchi, S., N. Araki and Y. Morino, 1991. Immunochemical approach to characterize advanced glycation end products of the meillard reaction. Evidence for the presence of a common structure. J. Biol. Chem., 266: 7329-7332. PMID: 2019568

Hsia, C.H., C.H. Wang, Y.W. Kuo, Y.J. Ho and H.L. Chen, 2012. Fructo-oligosaccharide systemically diminished D-galactose-induced oxidative molecule damages in BLB/cJ mice. Br. J. Nutr., 107: 17871792. PMID: 21929837

Kay, M., 2013. Physiologic autoantibody and immunoglobulin interventions during aging. Curr. Aging Sci., 6: 56-62. PMID: 23895522

Lei, M., X. Hua, M. Xiao, J. Ding and Q. Han et al., 2008. Impairments of astrocyte are involved in the D-galactose-induced brain aging. Biochem. Biophys. Res. Commun., 369: 1082-1087. PMID: 18329384

Lerner, A., T.M. Rossi, B. Park, B. Albini and E. Lebenthal, 1989. Serum antibodies to cow's milk proteins in pediatric inflammatory bowel disease: Crohn's Disease Vs. ulcerative colitis. Acta. Paediatr. Scand., 78: 384-389. PMID: 2919527

Luevano-Contreras, C. and K. Chapman-Novakofski, 2010. Dietary advanced glycation end products and aging. Nutrients, 2: 1247-1265. PMID: 22254007

Morohoshi, K., N. Patel, M. Ohbayashi, V. Chong and H.E. Grossniklaus et al., 2012. Serum autoantibody biomarkers for age-related macular degeneration and possible regulators of neovascularization. Exp. Mol. Pathol., 92: 64-73. PMID: 22001380
Nass, N., B. Bartling, A. Navarrete Santos, R.J. Scheubel and J. Borgermann et al., 2007. Advanced glycation end products, diabetes and ageing. Z. Gerontol. Geriatr., 40: 349-356. PMID: 17943238

Odetti, P., S. Rossi, F. Monacelli, A. Poggi and M. Cirnigliaro et al., 2005. Advanced glycation end products and bone loss during aging. Ann. N. Y. Acad. Sci., 1043: 710-717. PMID: 16037297

Osawa, T. and Y. Kato, 2005. Protective role of antioxidative food factors in oxidative stress caused by hyperglycemia. Ann. N. Y. Acad. Sci., 1043: 440451. PMID: 16037265

Park, J.H. and T.S. Choi, 2012. Polycystic Ovary Syndrome (PCOS)-like phenotypes in the Dgalactose induced aging mouse model. Biochem. Biophys. Res. Commun., 427: 701-704. PMID: 23022527

Pietropaolo, M., L. Castano, S. Babu, R. Buelow and Y.L. Kuo et al., 1993. Islet Cell Autoantigen 69kD (ICA69). Molecular cloning and characterization of a novel diabetes-associated autoantigen. J. Clin. Invest., 92: 359-371. PMID: 8326004

Rasheed, Z., L. Kumar, Sajid, I. Prasad and N.A. Ansari, 2009. Advanced Glycation End products (AGEs) Damaged IgG, a Target for circulating autoantibodies in patients with type 1 diabetes mellitus. Open Glycosci., 2: 1-8. DOI: 10.2174/1875398100902010001

Ronningen, K.S., A. Atrazhev, L. Luo, C. Luo and DK. Smith, 1998. Anti-BSA antibodies do not cross-react with the $69-\mathrm{kDa}$ islet cell autoantigen ICA69. J. Autoimmun., 11: 223-231. PMID: 9693970

Rumble, J.R., ME. Cooper, T. Soulis, A. Cox and L. Wu et al., 1997. Vascular hypertrophy in experimental diabetes. Role of advanced glycation end products. J. Clin. Invest., 99: 1016-1027. PMID: 9062360

Scott, F.W., J.M. Norris and H. Kolb, 1996. Milk and type I diabetes. Diabetes Care., 19: 379-383. PMID: 8729165

Shibayama, R., N. Araki, R. Nagai and S. Horiuchi, 1999. Autoantibody Against N(Carboxymethyl)lysine an advanced glycation end product of the maillard reaction. Diabetes, 48: 18421849. PMID: 10480617

Shuvaev, V.V., I. Laffont, J.M. Serot, J. Fujii and N. Taniguchi et al., 2001. Increased protein glycation in cerebrospinal fluid of Alzheimer's disease. Neurobiol. Aging, 22: 397-402. PMID: 11378244

Song, X., M. Bao, D. Li and Y.M. Li, 1999. Advanced glycation in D-galactose induced mouse aging model. Mech. Ageing Dev., 108: 239-251. PMID: 10405984 
Turk, Z., S. Liubic, N. Turk and B. Benko, 2001. Detection of autoantibodies against advanced glycation endproducts and AGE-immune complexes in serum of patients with diabetes mellitus. Clin. Chim. Acta., 303: 105-115. PMID: 11163030

Wang, C.Y., H.J. Liu, H.J. Chen, Y.C. Lin and H.H. Wang et al., 2011. AGE-BSA down regulates endothelial connexin43 gap junctions. BMC Cell Biol., 16: 12-19. PMID: 21575204

Wasserfall, C.H. and M.A. Atkinson, 2006. Autoantibody markers for the diagnosis and prediction of type 1 diabetes. Autoimmun Rev., 5: 424-428. PMID: 16890898

Wu, L., Y. Sun, Y.J. Hu, Y. Yang and L.L. Yao et al., 2012. Increased p66Shc in the inner ear of Dgalactose-induced aging mice with accumulation of mitochondrial DNA 3873-bp deletion: p66Shc and mtDNA damage in the inner ear during aging. PLoS One, 7: e50483. PMID: 23209752
Xie, S. and X. Ling, 2008. Regulative effects of auricular acupuncture, moxibustion and chinese herbs on immunologic function in the D-galactose-induced aging mouse. J. Tradit. Chin. Med., 28: 129-133. PMID: 18652121

Yokota, A., Y. Yamaguchi, Y. Ueda, T. Nakanishi and N. Ikari et al., 1990. Comparison of islet cell antibodies, islet cell surface antibodies and antibovine serum albumin antibodies in type 1 diabetes. Diabetes Res. Clin. Pract., 9: 211-217. PMID: 2226120

Ziegler, A.G. and E. Bonifacio, 2012. Age-related islet autoantibody incidence in offspring of patients with type 1 diabetes. Diabetologia., 55: 1937-1943. PMID: 22289814 